\title{
LAS NUEVAS FORMAS DE VIDA CONSAGRADA Y LANUEVA EVANGELIZACIÓN
}

DOI: https://doi.org/10.52039/seminarios.v61i213.188

LOURDES GROSSO GARCÍA*

«Que todos sean uno: como tú, Padre, estás en mí y yo en ti, que también ellos sean uno en nosotros, para que el mundo crea que tú me has enviado» (Jn 17, 21).

\section{PREFACIO}

En la Redemptoris missio ${ }^{1}$, san Juan Pablo II insiste con fuerza en la unión de todos los miembros de la Iglesia para la realización del siempre urgente mandato misionero, subrayando que «ha llegado el momento de dedicar todas las fuerzas eclesiales a la nueva evangelización y a la misión ad gentes. Ningún creyente en Cristo, ninguna institución de la Iglesia puede eludir este deber supremo: anunciar a Cristo a todos los pueblos». La imperiosa necesidad de anunciar el evangelio a cuantos aún no lo han conocido, y especialmente descubrir cómo hacer llegar el mensaje de Cristo a los jóvenes no cristianos, que son el futuro de continentes enteros, sin descuidar los areópagos modernos donde se produce la cultura y los nuevos modelos de desarrollo, son los retos con los que entraremos en el nuevo siglo (cf. Redemptoris missio, 37).

Por ello, agradezco de todo corazón al Director de la Revista Seminarios que me haya invitado a escribir un artículo en el que se aborde el tema de la misión evangelizadora, en esta hora de la nueva evangelización, desde la labor que realiza la vida consagrada, y más concretamente, las nuevas formas de vida consagrada, gratitud que se ve incrementada por mi condición personal de «misionera Idente», esto es, miembro de un instituto considerado nueva forma de Vida Consagrada.

En la realización de este trabajo tenemos muy presente la exhortación apostólica postsinodal Vita consecrata, de san Juan Pablo II, en la que se subraya la necesidad de promover la comunión eclesial, de manera especial entre el cle-

* Misionera Idente, Directora del Secretariado de la Comisión Episcopal de Vida Consagrada. Consultora de la Congregación para los Institutos de Vida consagrada y las Sociedades de Vida Apostólica.

1. San Juan Pablo II, Encíclica Redemptoris Missio. Sobre la permanente validez del mandato misionero (7-12-1990) 3; cf. 37. 
ro secular y los consagrados, aseverando que «contribuirá también a un mejor conocimiento recíproco, a la inserción de la teología y de la espiritualidad de la vida consagrada en el plan de estudios teológicos de los presbíteros diocesanos, así como la previsión en la formación de las personas consagradas de un adecuado estudio de la teología de la Iglesia particular y de la espiritualidad del clero diocesano $»^{2}$. Esta recomendación venía ya recogida en el decreto conciliar Optatam totius ${ }^{3}$, sobre la formación sacerdotal, donde se pide que los seminaristas «aprendan con igual cuidado a ayudar a los religiosos y religiosas para que perseveren en la gracia de su propia vocación y progresen según el espíritu de los diversos Institutos».

Es necesario conocer de cerca esta parcela del Pueblo de Dios, por lo que espero que estas líneas constituyan un acercamiento cordial a la vida consagrada, y en este caso especialmente a las nuevas formas de vida consagrada. Ojalá que en este Año de la Vida Consagrada toda la Iglesia, comenzando por los pastores, tenga la oportunidad de retomar la lectura de la exhortación apostólica postsinodal Vita consecrata, pues una mirada atenta a este precioso documento, auténtico vademécum de la vida consagrada, servirá de manera especial a los sacerdotes y seminaristas, y les recordará muchos temas paralelos de la también exhortación apostólica postsinodal Pastores dabo vobis, especialmente en todo cuanto se refiere al seguimiento radical de Cristo (Esposo, Buen Pastor), en la Iglesia misterio, comunión y misión, donde estamos llamados a vivir cada vez con mayor intensidad la relación íntima y personal con Cristo y ser signo de su presencia y acción en el mundo.

Son necesarias iniciativas que promuevan la comunión eclesial entre todos los ministerios y carismas. Esta es una de las expectativas que tiene el Papa Francisco, según indica en la carta apostólica que dirige a todos los consagrados con ocasión del Año de la Vida Consagrada, en la que nos dice: «Los religiosos y las religiosas, al igual que todas las demás personas consagradas, están llamadas a ser «expertos en comunión». Espero, por tanto, que la «espiritualidad de comunión», indicada por san Juan Pablo II, se haga realidad y que vosotros estéis en primera línea para acoger «el gran desafío que tenemos ante nosotros» en este nuevo milenio: «Hacer de la Iglesia la casa y la escuela de la comunión» (Novo millennio ineunte, 43). Estoy seguro de que este Año trabajaréis con seriedad para que el ideal de fraternidad perseguido por los fundadores y fundadoras crezca en los más diversos niveles, como en círculos concéntricos [...] La comunión y el encuentro entre diferentes carismas y vocaciones es un camino de esperanza. Nadie construye el futuro aislándose, ni sólo con sus propias fuerzas, sino reconociéndose en la verdad de una comunión que siempre se abre al encuentro, al diálogo, a la escucha, a la ayuda mutua, y nos preserva de la

2. San Juan Pablo II, Vita consecrata, 50.

3. Optatam totius. Sobre la formación sacerdotal (28-10-1965), 19. 
enfermedad de la auto-referencialidad $\aleph^{4}$. La comunión será posible en la medida en que la busquemos desde la convicción de su necesidad y la construyamos en nuestros ambientes, día a día, con pequeños gestos que la generan.

\section{INTRODUCCIÓN}

La evangelización obedece al mandato misionero de Jesús: «ld y haced que todos los pueblos sean mis discípulos, bautizándolos en el nombre del Padre y del Hijo y del Espíritu Santo, enseñándoles a observar todo lo que os he mandado» (Mt 28, 19-20). El Señor Resucitado envía a los suyos a predicar el Evangelio en todo tiempo y por todas partes, de manera que la fe en Él se difunda en cada rincón de la tierra. «En la Palabra de Dios aparece permanentemente este dinamismo de «salida» que Dios quiere provocar en los creyentes. Abraham aceptó el llamado a salir hacia una tierra nueva (cf. Gn 12,1-3). Moisés escuchó el llamado de Dios: «Ve, yo te envío» (Ex 3, 10), e hizo salir al pueblo hacia la tierra de la promesa (cf. Ex 3, 17). A Jeremías le dijo: «Adondequiera que yo te envíe irás» (Jr 1, 7). Hoy, en este «id» de Jesús, están presentes los escenarios y los desafíos siempre nuevos de la misión evangelizadora de la Iglesia, y todos somos llamados a esta nueva «salida» misionera. Cada cristiano y cada comunidad discernirá cuál es el camino que el Señor le pide, pero todos somos invitados a aceptar este llamado: salir de la propia comodidad y atreverse a llegar a todas las periferias que necesitan la luz del Evangelio» ${ }^{5}$.

El contexto eclesial en que ha de situarse la presente reflexión es el Año de la Vida Consagrada, convocado por el Papa Francisco, haciéndose eco del sentir de muchos, con motivo del 50 aniversario de la Constitución dogmática Lumen Gentium, así como del Decreto Perfectae caritatis sobre la renovación de la vida religiosa. Junto a ello, nos ilumina la Evangelii gaudium de Papa Francisco, dado que es un texto programático de su pontificado, como indica expresamente: «En esta Exhortación quiero dirigirme a los fieles cristianos para invitarlos a una nueva etapa evangelizadora marcada por esa alegría, e indicar caminos para la marcha de la Iglesia en los próximos años» ${ }^{6}$. Además, no perdamos de vista que Evangelii gaudium, que trata sobre El anuncio del Evangelio en el mundo actual es una exhortación apostólica, y aunque no se denomine «postsinodal» recoge las proposiciones de la XIII Asamblea Ordinaria del Sínodo de los Obispos, celebrada en 2012 sobre La nueva evangelización para la transmisión de la fe cristiana. Tenemos siempre de fondo el marco teológico de la exhortación apostólica postsinodal Vita consecrata de san Juan Pablo Il que es referencia obligada para comprender teológica y vivencialmente qué es la vida consagrada.

4. Papa Francisco, Carta apostólica a todos los consagrados con ocasión del Año de la vida Consagrada, 21 de noviembre de 2014, II.

5. Papa Francisco, Evangelii gaudium, 20.

6. Ibid., 1. 
Para cumplir el objetivo de este escrito, esto es, mostrar qué son las «nuevas formas de vida consagrada» (NFVC) y su aportación a la misión evangelizadora de la Iglesia, en concreto a la Nueva Evangelización, me sirvo de las publicaciones citadas en la referencia bibliográfica que señalo al final, especialmente de la obra Multiforme armonía. Actualidad teológico-canónica de las Nuevas Formas de Vida Consagrada, que acaba de publicar la BAC, pues es una monografía fruto de cuatro años de trabajo de un «seminario» de expertos convocados por la Comisión Episcopal para la Vida Consagrada. En la redacción de este libro se ha trabajado directamente sobre las Constituciones de los cinco institutos de derecho pontificio reconocidos como NFVC, y además se ha seguido el esquema general que indica la Congregación para los Institutos de Vida Consagrada y Sociedades de Vida Apostólica para la redacción de las Constituciones ${ }^{7}$, con el deseo de facilitar el trabajo a las nuevas realidades que están en proceso de reconocimiento canónico.

En la introducción de esta obra, encontramos una afirmación referida a la misión de las NFVC, que expresa de forma sintética el objetivo de nuestra reflexión. Dice lo siguiente: «Las NFVC, además de ofrecer un nuevo ardor y unas nuevas expresiones apostólicas, expresan la comunión multiforme del pueblo de Dios como verdadero sujeto de la misión de la Iglesia y, esto, como tarea irrenunciable» $(X X X I I I)^{8}$. Es decir, la misión, la Nueva evangelización, se realiza desde la comunión.

Las NFVC, unidas a las de mayor tradición en la historia de la Iglesia, acogen el mandato siempre vigente de predicar el Evangelio en todo tiempo, en toda circunstancia y por todos los lugares, de manera que la buena noticia se difunda en cada rincón de la tierra. «El Espíritu interpela a la vida consagrada para que -con una nueva imaginación de la caridad- elabore nuevas respuestas a los nuevos problemas del mundo de hoy, actuando con audacia en los campos respectivos del propio carisma fundacional, elaborando y llevando a cabo nuevos proyectos de evangelización para las situaciones actuales; esto alcanza especial relieve en esta hora de la nueva evangelización, en la que la vida consagrada, en las antiguas y nuevas formas, tiene un gran tarea que desempeñar ${ }^{9}$.

Antes de entrar en lo específico del tema, es necesario que nos detengamos a precisar qué entendemos por Nueva Evangelización y por Nuevas Formas de Vida Consagrada.

7. Cf. «Esquema general acerca de la redacción de las Constituciones de una Asociación de hombres célibes y mujeres célibes consagrados/as con vistas a ser erigida en Instituto de Vida Consagrada (2002)», en L. Grosso García (ed.), Itinerarios del Espíritu. Experiencias y prospectivas de las Nuevas Formas de Vida Consagrada, Madrid 2013, 149-154.

8. Seminario de NFVC, Multiforme armonía. Actualidad teológico-canónica de las Nuevas Formas de Vida Consagrada, Madrid 2015, XXXIII.

9. Conferencia Episcopal Española, Iglesia particular y vida consagrada. Cauces operativos para facilitar las relaciones mutuas entre los obispos y la vida consagrada de la lglesia en España, Madrid 2013, 58. 


\section{NUEVA EVANGELIZACIÓN Y NUEVOS EVANGELIZADORES}

La expresión Nueva Evangelización es mucho más que un eslogan o un concepto logrado que ha cuajado en el lenguaje y la literatura eclesial de las últimas décadas ${ }^{10}$.

Juan Pablo II utiliza esta terminología desde el comienzo de su pontificado; la escuchábamos de sus labios por primera vez en la ciudad de Cracovia el 9 de junio de 1979 y después en Haití el 9 de marzo de 1983. El concepto se extiende a la Iglesia universal a través de la exhortación apostólica postsinodal Christifideles laici (1988) y en la encíclica Redemptoris missio (1990), y con él nos urgía a los fieles a cumplir una tarea evangelizadora nueva: «nueva en su ardor, en sus métodos y en su expresión» ${ }^{11}$.

Benedicto XVI viendo «la necesidad de ofrecer una respuesta particular al momento de crisis de la vida cristiana que se está comprobando en muchos países, sobre todo de antigua tradición cristiana» ${ }^{12}$, colocó la nueva evangelización en el primer puesto de toda la Iglesia: convocó el Sínodo de obispos para la nueva evangelización (octubre 2012) y creó un nuevo dicasterio: el Pontificio Consejo para la Promoción de la Nueva Evangelización.

Sobre todo la novedad es el Evangelio mismo, la Buena Nueva arraigada en el corazón mismo de quien anuncia. Nueva Evangelización es, antes que nada, nuevos evangelizadores (que es una de las expresiones que utiliza el Papa Francisco). Y también es reconocer ámbitos de misión nuevos o que implican de algún modo una novedad evangelizadora.

El Instrumentum laboris del Sínodo sobre la Nueva Evangelización explica claramente que: La nueva evangelización, asumida como exigencia, ha llevado a la Iglesia a examinar el modo según el cual las comunidades cristianas actualmente viven y dan testimonio de la propia fe. La nueva evangelización se ha transformado de este modo en discernimiento, es decir, en capacidad de leer y descifrar los nuevos escenarios, que en estas últimas décadas se han creado en la historia de los hombres, para convertirlos en lugares de anuncio del Evangelio y de experiencia eclesial ${ }^{13}$.

Es decir, se requieren testigos, personas y comunidades que den testimonio y sepan convertir los nuevos escenarios en lugares de anuncio y vivencia del Evangelio.

Benedicto XVI, en la homilía de clausura del citado Sínodo subrayará que «los verdaderos protagonistas de la Nueva Evangelización son los santos: ellos

10. Cf. Juan Pablo II, Vita consecrata, 81; Papa Francisco, Evangelii gaudium, 1. 17.69.287.

11. Juan Pablo II, Discurso a la Asamblea del CELAM (9-3-1983).

12. Benedicto XVI, Discurso a la Plenaria del Pontificio Consejo para la Promoción de la Nueva Evangelización (20-5-2011).

13. Sínodo de los Obispos. XIII Asamblea general ordinaria, La nueva evangelización para la transmisión de la fe cristiana. Instrumentum Laboris (27-5-2012) 51. 
hablan un lenguaje comprensible para todos, con el ejemplo de la vida y con las obras de caridad» $»^{14}$.

El n. 81 de Vita consecrata está dedicado a la nueva evangelización. Una lectura detenida nos aporta criterios importantes para reconocer el papel de los consagrados:

-los consagrados y consagradas hemos de hacer frente de manera adecuada a los grandes desafíos que la historia pone a la nueva evangelización, estando dispuestos a responder con sabiduría evangélica a los interrogantes que hoy brotan de la inquietud del corazón humano y de sus necesidades más urgentes;

-el primer requisito para ello es que seamos personas entregadas amorosamente al Señor y a su evangelio, y tengamos muy presente que los grandes evangelizadores y evangelizadoras fueron antes grandes evangelizados;

-esto se manifestará con las siguientes características vitales y apostólicas: testimonio audaz, confianza en la Providencia, fidelidad al carisma fundacional, comunión con todos aquellos que en la Iglesia están comprometidos en la misma empresa, especialmente con los Pastores, y cooperación con todos los hombres de buena voluntad;

- para ser evangelizadores hemos de dejarnos interpelar por la Palabra revelada y por los signos de los tiempos, con plena conciencia del sentido teológico de los retos de nuestro tiempo, para poder discernir las llamadas que el Espíritu dirige a cada Instituto.

-las personas consagradas serán pregoneras entusiastas del Señor Jesús en todo tiempo y lugar, proclamando desde los tejados lo que han vivido en la intimidad con el Señor. Sólo así la nueva evangelización, como la de siempre, será eficaz.

Ahondando en los criterios mencionados, es importante detenernos en una visión sintética de la respuesta de la vida consagrada ante los desafíos de la sociedad posmoderna, que ofrece Vita consecrata en los números 84-95.

En primer lugar se pide a las personas consagradas un testimonio profético, que «exige la búsqueda apasionada y constante de la voluntad de Dios, la generosa e imprescindible comunión eclesial, el ejercicio del discernimiento espiritual y el amor por la verdad. También se manifiesta en la denuncia de todo aquello que contradice la voluntad de Dios y en el escudriñar nuevos caminos de actuación del Evangelio para la construcción del Reino de Dios» (84). «Aquellos que siguen los consejos evangélicos, al mismo tiempo que buscan la propia santificación, proponen, por así decirlo, una «terapia espiritual» para la humanidad, puesto que rechazan la idolatría de las criaturas y hacen visible de algún modo al Dios viviente. La vida consagrada, especialmente en los momentos de dificultad, es una bendición para la vida humana y para la misma vida eclesial» (87).

14. Benedicto XVI, Homilía en la Celebración de la Eucaristía de conclusión de la XIII Asamblea General Ordinaria del Sínodo de los Obispos (28-10-2012). 
El cometido profético de la vida consagrada se encuentra hoy con tres desafíos principales que atañen directamente a los consejos evangélicos:

-la provocación de la cultura hedonística que deslinda la sexualidad de cualquier norma moral objetiva. A ello la vida consagrada responde con la práctica gozosa de la castidad perfecta (cf. 88);

-la provocación del materialismo ávido de poseer, desinteresado de las exigencias de los más débiles y del equilibrio de los recursos naturales. A ello la vida consagrada responde con la profesión de la pobreza evangélica y un compromiso activo en la promoción de la solidaridad y de la caridad (cf. 89-90);

-la provocación que proviene de las concepciones de libertad que prescinden de su relación constitutiva con la verdad y con la norma moral. A ello la vida consagrada responde con la práctica de la obediencia, manifestada en una conciencia filial que desea asumir la voluntad del Padre como alimento cotidiano (cf. 91).

La respuesta a estos desafíos se dará en la medida en que «la vida consagrada se nutra en las fuentes de una sólida y profunda espiritualidad» (93), mediante la escucha de la Palabra de Dios (cf. 94), la celebración eucarística, la vida de piedad y oración (cf. 95).

También el Papa Francisco se ha referido a la necesidad de la Nueva Evangelización, si bien utiliza en la Evangelii gaudium las expresiones Nueva etapa evangelizadora ${ }^{15}$, Nuevos procesos de evangelización ${ }^{16}$. En el contexto tanto de la citada exhortación apostólica como de las frecuentes manifestaciones del Santo Padre, podemos entender bien cuáles son las prioridades que nos marca. Dirigiéndose a los participantes en la Plenaria del Pontificio Consejo para la promoción de la Nueva Evangelización señaló estos tres puntos ${ }^{17}$ :

-primado del testimonio: En nuestro tiempo se verifica a menudo una actitud de indiferencia hacia la fe [...] Nueva evangelización significa despertar en el

15. Papa Francisco, Evangelii gaudium: «La alegría del Evangelio llena el corazón y la vida entera de los que se encuentran con Jesús. Quienes se dejan salvar por Él son liberados del pecado, de la tristeza, del vacío interior, del aislamiento. Con Jesucristo siempre nace y renace la alegría. En esta Exhortación quiero dirigirme a los fieles cristianos para invitarlos a una nueva etapa evangelizadora marcada por esa alegría, e indicar caminos para la marcha de la Iglesia en los próximos años» (1). «Aquí he optado por proponer algunas líneas que puedan alentar y orientar en toda la Iglesia una nueva etapa evangelizadora, llena de fervor y dinamismo» (17). «A la Madre del Evangelio viviente le pedimos que interceda para que esta invitación a una nueva etapa evangelizadora sea acogida por toda la comunidad eclesial. [...] Nosotros hoy fijamos en ella la mirada, para que nos ayude a anunciar a todos el mensaje de salvación, y para que los nuevos discípulos se conviertan en agentes evangelizadores» (287).

16. Ibíd., 69: «Es imperiosa la necesidad de evangelizar las culturas para inculturar el Evangelio. En los países de tradición católica se tratará de acompañar, cuidar y fortalecer la riqueza que ya existe, y en los países de otras tradiciones religiosas o profundamente secularizados se tratará de procurar nuevos procesos de evangelización de la cultura, aunque supongan proyectos a muy largo plazo. No podemos, sin embargo, desconocer que siempre hay un llamado al crecimiento. Toda cultura y todo grupo social necesitan purificación y maduración».

17. Cf. Papa Francisco, Discurso a los participantes en la Plenaria del Pontificio Consejo para la promoción de la Nueva Evangelización (14-10-2013). 
corazón y en la mente de nuestros contemporáneos la vida de la fe [...]. Lo que necesitamos, especialmente en estos tiempos, son testigos creíbles que con la vida y también con las palabras hagan visible el Evangelio, despierten la atracción por Jesucristo, por la belleza de Dios.

- urgencia de ir al encuentro: La nueva evangelización es un movimiento renovado hacia quien ha perdido la fe y el sentido profundo de la vida. Este dinamismo forma parte de la gran misión de Cristo de traer vida al mundo, el amor del Padre a la humanidad. El Hijo de Dios «salió» de su condición divina y vino a nuestro encuentro. [...] Podemos ir al encuentro de todos, sin miedo y sin renunciar a nuestra pertenencia.

-proyecto pastoral centrado en lo esencial: Todo esto, sin embargo, en la Iglesia no se deja a la casualidad, a la improvisación. Exige el compromiso común para un proyecto pastoral que remita a lo esencial y que esté bien centrado en lo esencial, es decir, en Jesucristo. [...] Un encuentro con Cristo que es también adoración, palabra poco usada: adorar a Cristo. Un proyecto animado por la creatividad y por la fantasía del Espíritu Santo, que nos impulsa también a recorrer nuevas vías con valentía, sin fosilizarnos.

\section{NuEVAS Formas dE VIDA CONSAGRAdA}

La primera cuestión a tener en cuenta cuando se habla de «vida consagrada» es que, en términos generales, se refiere a la vida de seguimiento de Cristo por la profesión de los consejos evangélicos, lo que puede hacerse desde formas variadas. La vida consagrada es seguir a Cristo para llevar el Evangelio del amor de Dios al mundo, lo que se traduce en un estilo de vida y de obras.

Las formas principales de los institutos de vida consagrada son: vida monástica (es decir monjes y monjas), el orden de las vírgenes, los eremitas, la vida contemplativa, la vida religiosa apostólica (congregaciones, institutos religiosos), los institutos seculares, las nuevas formas de vida consagrada, y se añaden las sociedades de vida apostólica.

Los consagrados y consagradas viven en un contexto sociocultural concreto, que les impacta, reta y desafía. A esta sociedad concreta son enviados como testigos de Jesucristo para seguir proclamando la buena nueva de la salvación. Desde una perspectiva sociológica y en la búsqueda de cómo interrelacionarse con el mundo actual, es importante el acento sobre la vida comunitaria, porque la vivencia de la consagración en comunidad es auténtico testimonio para el mundo de hoy. De ahí la necesidad de comunidades (pequeñas o grandes, no es cuestión de número) donde se den auténticas relaciones humanas y espirituales: "Con la constante promoción del amor fraterno en la forma de vida común, la vida consagrada pone de manifiesto que la participación en la comunión trinitaria puede transformar las relaciones humanas, creando un nuevo tipo de solidaridad. Ella indica de este modo a los hombres tanto la belleza de la comu- 
nión fraterna, como los caminos concretos que a ésta conducen. Las personas consagradas, en efecto, viven «para» Dios y «de» Dios. Por eso precisamente pueden proclamar el poder reconciliador de la gracia, que destruye las fuerzas disgregadoras que se encuentran en el corazón humano y en las relaciones sociales $^{18}$.

La vida consagrada tiene una vocación urgente de ser signo de la gran familia de Dios, de la gran amplitud del Reino, al que todos pertenecen.

En apenas cinco décadas se han producido cambios profundos en la sociedad y en la forma en que la Iglesia se dirige a ella llevando el mensaje de Cristo, es decir, el Evangelio. La vida consagrada es reflejo de ello, tanto en la renovación de congregaciones seculares como en el nacimiento de otras que responden a las necesidades de estos tiempos.

Un «grupo», para poder ser considerado «vida consagrada» requiere un largo proceso de discernimiento eclesial. No basta que un conjunto de buenas personas se reúnan para hacer el bien. Cuando nos referimos a NFVC estamos ante expresiones de la vida consagrada que acogen, en la actual situación histórica, las instancias profundas de búsqueda de sentido y de finalidad últimas del corazón humano, y son testimonio de la acción del Espíritu que en cada momento vivifica su Iglesia. Tienen el propósito de expresar de una u otra manera el misterio de la Iglesia, queriendo responder a las nuevas necesidades que la Iglesia encuentra hoy al realizar su misión en el mundo; se trata de nuevas expresiones del carisma, generalmente ante la necesidad de responder a nuevos retos evangelizadores. De ahí que una mirada a la historia nos permita constatar el continuo sucederse de nuevas formas de consagración. Cuando iniciaron, fueron nueva forma la vida monástica, las órdenes mendicantes, las congregaciones religiosas, los institutos seculares. "Las Nuevas Formas son una realidad querida por el Espíritu Santo para la Iglesia, que se añaden a las antiguas pero sin suplantarlas y que con características novedosas conservan la unidad y esencia de la vida consagrada de siempre como don perenne de Cristo a su Iglesia» ${ }^{19}$. En los últimos años han surgido institutos y asociaciones que, aunque se consideran «vida consagrada» ${ }^{20}$, tienen una configuración peculiar; se vienen denominando familia eclesial ${ }^{21}$.

En la exhortación apostólica postsinodal Vita consecrata, hay dos importantes referencias, que nos aportan la visión de qué se entiende actualmente por NFVC. Dada la importancia de estos textos y el carácter divulgativo de la presente publicación, reproducimos a continuación los dos números íntegros:

18. Vita consecrata, 41.

19. L. Grosso García (ed.), Mirad cómo se aman..., 29.

20. Es decir, presentan las características propias de la vida consagrada según recoge el Código de Derecho Canónico pero tienen, además, otras peculiaridades propias.

21. Cf. L. Grosso García (ed.), Ibid, 27. 


\section{Nuevas formas de vida consagrada}

«La perenne juventud de la Iglesia continúa manifestándose también hoy: en los último s decenios, después del Concilio Ecuménico Vaticano II, han surgido nuevas o renovadas formas de vida consagrada. En muchos casos se trata de Institutos semejantes a los ya existentes, pero nacidos de nuevos impulsos espirituales y apostólicos. Su vitalidad debe ser discernida por la autoridad de la Iglesia, a la que corresponde realizar los necesarios exámenes tanto para probar la autenticidad de la finalidad que los ha inspirado, como para evitar la excesiva multiplicación de instituciones análogas entre sí, con el consiguiente riesgo de una nociva fragmentación en grupos demasiado pequeños. En otros casos se trata de experiencias originales, que están buscando una identidad propia en la Iglesia y esperan ser reconocidas oficialmente por la Sede Apostólica, única autoridad a la que compete el juicio último.

Estas nuevas formas de vida consagrada, que se añaden a las antiguas, manifiestan el atractivo constante que la entrega total al Señor, el ideal de la comunidad apostólica y los carismas de fundación continúan teniendo también sobre la generación actual y son además signo de la complementariedad de los dones del Espíritu Santo.

Además, el Espíritu en la novedad no se contradice. Prueba de esto es el hecho de que las nuevas formas de vida consagrada no han suplantado a las precedentes. En tal multiforme variedad se ha podido conservar la unidad de fondo gracias a la misma llamada a seguir, en la búsqueda de la caridad perfecta, a Jesús virgen, pobre y obediente. Esta llamada, tal como se encuentra en todas las formas ya existentes, se pide del mismo modo en aquellas que se proponen como nuevas» ${ }^{22}$.

\section{Nuevas formas de vida evangélica}

«El Espíritu, que en diversos momentos de la historia ha suscitado numerosas formas de vida consagrada, no cesa de asistir a la Iglesia, bien alentando en los Institutos ya existentes el compromiso de la renovación en fidelidad al carisma original, bien distribuyendo nuevos carismas a hombres y mujeres de nuestro tiempo, para que den vida a instituciones que respondan a los retos del presente. Un signo de esta intervención divina son las llamadas nuevas Fundaciones, con características en cierto modo originales respecto a las tradicionales.

La originalidad de las nuevas comunidades consiste frecuentemente en el hecho de que se trata de grupos compuestos de hombres y mujeres, de clérigos y laicos, de casados y célibes, que siguen un estilo particular de vida, a veces inspirado en una u otra forma tradicional, o adaptado a las exigencias de la sociedad de hoy. También su compromiso de vida evangélica se expresa de varias 
maneras, si bien se manifiesta, como una orientación general, una aspiración intensa a la vida comunitaria, a la pobreza y a la oración. En el gobierno participan, en función de su competencia, clérigos y laicos, y el fin apostólico se abre a las exigencias de la nueva evangelización.

Si de una parte hay que alegrarse por la acción del Espíritu, por otra es necesario proceder con el debido discernimiento de los carismas. El principio fundamental para que se pueda hablar de vida consagrada es que los rasgos específicos de las nuevas comunidades y formas de vida estén fundados en los elementos esenciales, teológicos y canónicos, que son característicos de la vida consagrada. Este discernimiento es necesario tanto a nivel local como universal, con el fin de prestar una común obediencia al único Espíritu. En las diócesis, el Obispo ha de examinar el testimonio de vida y la ortodoxia de los fundadores y fundadoras de tales comunidades, su espiritualidad, la sensibilidad eclesial en el cumplimiento de su misión, los métodos de formación y los modos de incorporación a la comunidad; evalúe con prudencia eventuales puntos débiles, sabiendo esperar con paciencia la confirmación de los frutos (cf. Mt 7, 16), para poder reconocer la autenticidad del carisma. Se le pide sobre todo que ponga especial cuidado en verificar, a la luz de criterios claros, la idoneidad de quienes solicitan el acceso a las Órdenes sagradas.

En virtud de este mismo principio de discernimiento, no pueden ser comprendidas en la categoría específica de vida consagrada aquellas formas de compromiso, por otro lado loables, que algunos cónyuges cristianos asumen en asociaciones o movimientos eclesiales cuando, deseando llevar a la perfección de la caridad su amor «como consagrado» ya en el sacramento del matrimonio, confirman con un voto el deber de la castidad propia de la vida conyugal y, sin descuidar sus deberes para con los hijos, profesan la pobreza y la obediencia. Esta obligada puntualización acerca de la naturaleza de tales experiencias, no pretende infravalorar dicho camino de santificación, al cual no es ajena ciertamente la acción del Espíritu Santo, infinitamente rico en sus dones e inspiraciones.

Ante tanta riqueza de dones y de impulsos innovadores, parece conveniente crear una Comisión para las cuestiones relativas a las nuevas formas de vida consagrada, con el fin de establecer criterios de autenticidad, que sirvan de ayuda a la hora de discernir y de tomar las oportunas decisiones. Entre otras tareas, tal Comisión deberá valorar, a la luz de la experiencia de estos últimos decenios, cuáles son las formas nuevas de consagración que la autoridad eclesiástica, con prudencia pastoral y para el bien común, pueda reconocer oficialmente y proponer a los fieles deseosos de una vida cristiana más perfecta.

Estas nuevas asociaciones de vida evangélica no son alternativas a las precedentes instituciones, las cuales continúan ocupando el lugar insigne que la tradición les ha reservado. Las nuevas formas son también un don del Espíritu, para que la Iglesia siga a su Señor en una perenne dinámica de generosidad, atenta a las llamadas de Dios que se manifiestan a través de los signos de los tiempos. 
De esta manera se presenta ante el mundo con variedad de formas de santidad y de servicio, como «señal e instrumento de la íntima unión con Dios y de la unidad de todo el género humano». Los antiguos Institutos, muchos de los cuales han pasado en el transcurso de los siglos por el crisol de pruebas durísimas que han afrontado con fortaleza, pueden enriquecerse entablando un diálogo e intercambiando sus dones con las fundaciones que ven la luz en este tiempo nuestro.

De este modo el vigor de las diversas instituciones de vida consagrada, desde las más antiguas a las más recientes, así como la vivacidad de las nuevas comunidades, alimentarán la fidelidad al Espíritu Santo, que es principio de comunión y de perenne novedad de vida» ${ }^{23}$.

\section{Definición canónica de vida consagrada}

En el Código de Derecho Canónico (1983), hay dos cánones que tratan de definir la vida consagrada (y que por tanto hay que tomar en cuenta para referirnos a las NFVC): el 207. 2, hablando en general de los fieles cristianos, y el 573, con el que empiezan las normas generales que afectan a toda la vida consagrada.

Canon 207. 2. En estos dos grupos (clérigos y laicos, 1) hay fieles que, por la profesión de los consejos evangélicos mediante votos u otros vínculos sagrados, reconocidos y sancionados por la Iglesia, se consagran a Dios y contribuyen a la misión salvífica de la Iglesia según la manera peculiar que les es propia; su estado, aunque no afecta a la estructura jerárquica de la Iglesia, pertenece, sin embargo, a la vida y santidad de la misma.

c. 573,1 . La vida consagrada por la profesión de los consejos evangélicos es una forma estable de vivir en la cual los fieles, siguiendo más de cerca a Cristo bajo la acción del Espíritu Santo, se dedican totalmente a Dios como a su amor supremo, para que entregados por un nuevo y peculiar título a su gloria, a la edificación de la Iglesia y a la salvación del mundo, consigan la perfección de la caridad en el servicio del Reino de Dios y, convertidos en signo preclaro en la Iglesia, preanuncien la gloria celestial.

2. Adoptan con libertad esta forma de vida en institutos de vida consagrada canónicamente erigidos por la autoridad competente de la Iglesia aquellos fieles que, mediante votos u otros vínculos sagrados, según las leyes propias de los institutos, profesan los consejos evangélicos de castidad, pobreza y obediencia, y, por la caridad a la que éstos conducen, se unen de modo especial a la Iglesia y a su misterio.

Ambos cánones manejan el mismo concepto que se halla en el Vaticano II, centrado en la profesión de los consejos de pobreza, castidad y obediencia.

23. Ibid, 62. 
Además de los cánones citados, y cuantos recogen las normas generales que ha de cumplir toda realidad que se denomine «vida consagrada», el Código de Derecho Canónico sabe que el Espíritu Santo puede inspirar otras formas de vida consagrada no previstas hasta ese momento. Así, dice el c. 605:

La aprobación de nuevas formas de vida consagrada se reserva exclusivamente a la Sede Apostólica. Sin embargo, los Obispos diocesanos han de procurar discernir los nuevos dones de vida consagrada otorgados a la Iglesia por el Espíritu Santo y ayudar a quienes los promueven para que formulen sus propósitos de la mejor manera posible y los tutelen mediante estatutos convenientes, aplicando sobre todo las normas generales contenidas en esta parte.

\section{Los rasgos más generales de las NFVC}

1. Una sola institución con miembros de los diferentes estados: célibes, clérigos, casados, y de ambos sexos: hombres y mujeres.

2. Profesión de los votos de pobreza, castidad y obediencia.

3. Vida común de los miembros que profesan la llamada castidad perfecta.

4. Un gobierno unificado en la cabeza de la Institución, con los respectivos superiores de las diferentes secciones o ramas: hombres, mujeres, matrimonios, clérigos.

5. Una fuerte espiritualidad y capacidad de evangelización, suelen trabajar como profesionales o empleados en los distintos ámbitos laborales, asistenciales y culturales, llegando a todos los rincones del mundo con su capacidad entusiasta de apostolado. Hay, no obstante quienes viven en conventos o monasterios, con régimen monástico.

6. Reconocimiento del valor de la comunión eclesial, con el deseo de poder ser ayuda a la Iglesia: en la parroquia, en la diócesis o en otros campos más generales y laicales, sea a nivel nacional o internacional.

7. Sentido y deseo de colaboración con otros grupos o instituciones religiosas para, juntos, poder realizar más fructíferamente la misión ad gentes.

8. Fuerte sentido de la hospitalidad y acogida, con una gran apertura.

9. Reconocimiento de la vida contemplativa, monástica, de oración, queriendo ser monjes en medio del mundo.

10. Hay algunos con una fuerte impronta monástica, viviendo la tradicional clausura y reglas, aunque tienen aspectos nuevos, como ser un único instituto con hombres y mujeres.

Tras esta breve pero necesaria concreción, para explicar qué entendemos al referirnos a los conceptos Nueva Evangelización y Nuevas Formas de Vida Consagrada, pasamos ahora a un análisis, también necesariamente concisa, sobre las Nuevas Formas de Vida Consagrada en la Nueva Evangelización. 


\section{Las NueVas Formas de Vida Consagrada en la NueVa EVANGELIZACIÓN}

«La llamada a la nueva evangelización informa la misión apostólica de las NFVC. Se anuncia el Evangelio ardientemente en las realidades y escenarios en los que viven inmersos aquellos que han olvidado el nombre del Señor. Aquellos pobres espirituales que viven en la periferia existencial $\sin$ Dios» ${ }^{24}$.

La nueva evangelización forma nuevos evangelizadores, que «salen al encuentro de los hombres en sus realidades concretas, cotidianas, respetando profundamente la dignidad de cada ser humano, le acompañan como familia espiritual en un itinerario de crecimiento en santidad, lo forman en la experiencia de la verdad, de la Palabra hecha vida, para que desde su unión personal con el Señor se convierta también él en un anunciador del Evangelio» ${ }^{25}$.

La exhortación Vita consecrata, resalta el valor de La fraternidad en un mundo dividido e injusto. "La Iglesia encomienda a las comunidades de vida consagrada la particular tarea de fomentar la espiritualidad de la comunión, ante todo en su interior y, además, en la comunidad eclesial misma y más allá aún de sus confines, entablando o restableciendo constantemente el diálogo de la caridad, sobre todo allí donde el mundo de hoy está desgarrado por el odio étnico o las locuras homicidas. Situadas en las diversas sociedades de nuestro mundo -frecuentemente laceradas por pasiones e intereses contrapuestos, deseosas de unidad pero indecisas sobre la vías a seguir-, las comunidades de vida consagrada, en las cuales conviven como hermanos y hermanas personas de diferentes edades, lenguas y culturas, se presentan como signo de un diálogo siempre posible y de una comunión capaz de poner en armonía las diversidades. Las comunidades de vida consagrada son enviadas a anunciar con el testimonio de la propia vida el valor de la fraternidad cristiana y la fuerza transformadora de la Buena Nueva, que hace reconocer a todos como hijos de Dios e incita al amor oblativo hacia todos, y especialmente hacia los últimos» ${ }^{26}$.

Esta vivencia de la fraternidad, característica de la eclesiología y la espiritualidad de comunión, está en el corazón mismo de las NFVC.

\section{La continua novedad del Espíritu}

En la vivencia de la comunión eclesial, el Espíritu se sirve de las NFVC para remarcar algunas características necesarias para la Iglesia, de las cuales «hay características que subrayan aspectos comunes con las formas tradicionales de vida consagradas; otras que son nuevas aportaciones, pero que pueden ser vividas por todos, y, finalmente, otras que son propias de las NFVC ${ }^{27}$. Lo hace:

24. Seminario de NFVC, Multiforme armonía, 156-157.

25. Ibid.

26. San Juan Pablo II, Vita consecrata, 51.

27. L. Grosso García (ed.), Mirad cómo se aman, 89. 
1. Recordando lo que es llamada universal, es decir, el Espíritu Santo se sirve de estas comunidades para recordarnos y poner de relieve aspectos de la vida eclesial que han de ser vividos por todos. Por ejemplo: el deseo de vivir la llamada universal a la santidad en la vida cotidiana; el deseo de comunión con la Iglesia universal y particular, valor que aparece recogido en los diversos Institutos como fidelidad al Papa, al magisterio, integración en los proyectos pastorales diocesanos, etc.

2. Desarrollando nuevos aspectos para vivencia de todos, esto es, aportando nuevos acentos que enriquecen a la comunidad eclesial y que pueden ser vividos por todos los consagrados, e incluso por todos los bautizados, por ejemplo: La referencia a la comunión trinitaria como modelo de la vida espiritual, y el ejemplo de la Sagrada Familia de Nazaret, que les dota de un fuerte sentido del espíritu familiar que marca la vida comunitaria y fraterna. O también, una forma de misión que se caracteriza por la acogida -con un fuerte sentido de la hospitalidad-y el acompañamiento personalizado que fluye de la necesidad de compartir los bienes del espíritu, integrando espiritualidad y capacidad de evangelización.

3. Abriendo caminos nuevos, esto es, aportando características que son propias de las NFVC, que hemos mencionado en los 10 puntos citados antes. En estas características radica la novedad respecto de la vida religiosa tradicional.

\section{Un modo de concreción de la eclesiología de comunión}

Todo lo expuesto nos lleva a afirmar que las NFVC, por la variedad de sus miembros y la peculiaridad de su vivencia, son una concreción carismática de la eclesiología de comunión y desde ella realizan su misión evangelizadora.

Algunas de sus manifestaciones son:

a) Familia eclesial de vida consagrada: unidad carismática de diversos estados de vida. Con las peculiaridades que hemos ido describiendo, «estas nuevas formas de vida consagrada, que se añaden a las antiguas, manifiestan el atractivo constante que la entrega total al Señor, el ideal de la comunidad apostólica y los carismas de fundación continúan teniendo también sobre la generación actual y son además signo de la complementariedad de los dones del Espíritu Santo ${ }^{28}$. Dado que esta complementariedad se da en el interior del propio instituto, como determinación carismática del mismo, podríamos hablar de familia eclesial de vida consagrada.

b) A vino nuevo, odres nuevos (Mc 2, 22): más allá de una estructura novedosa. Y si el Espíritu ha querido donar a la Iglesia una novedad teológica, no basta con aplicar moldes ya establecidos; convendrá encontrar las estructuras adecuadas para la misma, posiblemente con un desarrollo del can. 605 del Código de Derecho Canónico o con la oportuna legislación al respecto.

28. Vita consecrata, 12. 
c) Comunión como forma de ser: la caridad como vínculo de perfección (Col $3,14)$. La caridad es vínculo de la unidad perfecta, dirá San Pablo a la comunidad de los Colosenses. Este vínculo se va forjando entre los miembros del mismo instituto, que comparten la vocación carismática desde el propio estado de vida, y con toda la Iglesia. Parte de un espíritu de conversión personal y colegial. «La comunión es un don ofrecido que exige al mismo tiempo una respuesta, un paciente entrenamiento y una lucha para superar la simple espontaneidad y la volubilidad de los deseos. El altísimo ideal comunitario implica necesariamente la conversión de toda actitud que obstaculice la comunión. La comunidad sin mística no tiene alma, pero sin ascesis no tiene cuerpo. Se necesita "sinergia» entre el don de Dios y el compromiso personal para construir una comunión encarnada, es decir, para dar carne y concreción a la gracia y al don de la comunión fraterna» ${ }^{29}$.

d) Comunión como forma de actuar: comunicación de los bienes del Espíritu. Si la comunión es una forma de ser, será también la forma de actuar, que quedará de manifiesto en las obras que realicemos, en la misión que se nos asigne, pero sobre todo -porque aquí está la fuente- en la comunicación fraterna de la fe, de los bienes no sólo materiales sino también espirituales. «La exigencia más sentida de incrementar la vida fraterna de una comunidad lleva consigo la correspondiente necesidad de una más amplia e intensa comunicación» ${ }^{30}$.

El documento que la Congregación para los Institutos de Vida Consagrada y Sociedades de Vida Apostólica dedicó al tema de la vida fraterna en comunidad, denuncia claramente que son muchos los consagrados que expresan la necesidad de una comunicación más intensa entre los miembros de una misma comunidad, acusando que la falta de comunicación genera la debilidad de la comunidad, llegando a crear situaciones de aislamiento y de soledad, además del riesgo del individualismo, con la consiguiente autocefalía y autogestión. Una comunidad de consagrados no puede limitarse a compartir temas secundarios o superficiales, los vínculos se estrechan cuando se pone en común lo que es esencial, central y vital en la propia consagración: la comunicación de los bienes del Espíritu ${ }^{31}$. Ésta es una realidad que tienen muy en cuenta las NFVC.

e) Una respuesta del Espíritu ante el drama de la disolución de las familias. En las NFVC se da la peculiaridad de que hay personas casadas que se sienten llamadas a la misma vocación que las célibes y se integran, con las peculiaridades propias de su estado, en la vida del instituto. Pensando en ellas queremos subrayar, por último, que en una sociedad que ha quebrado la unión en matrimonio entre y un hombre y una mujer para formar una familia cristiana, que ha banalizado y desviado las relaciones humanas, son signo las personas que desean añadir al sacramento del matrimonio la profesión de un voto de castidad

29. La vida fraterna en comunidad (2-2-1994) 23.

30. Ibid, 29.

31. Cf. Ibid, 32. 
(conyugal) que les acompañe en la vivencia de la fidelidad al sacramento y al magisterio de la Iglesia, con las ayudas que proporciona un carisma. También será necesario explicar la peculiaridad de los vínculos sagrados de pobreza y obediencia para las personas casadas.

La propuesta del Evangelio sobre la familia en el contexto de crisis social y espiritual actual, resulta particularmente urgente y necesaria. Así leemos en el Documento preparatorio de la III Asamblea General Extraordinaria del Sínodo de los Obispos, Los desafíos pastorales sobre la familia en el contexto de la evangelización:

Hoy se presentan problemáticas inéditas hasta hace unos pocos años, desde la difusión de parejas de hecho, que no acceden al matrimonio y a veces excluyen la idea del mismo, a las uniones entre personas del mismo sexo [...], la cultura de la falta de compromiso y de la presupuesta inestabilidad del vínculo; formas de feminismo hostil a la Iglesia; fenómenos migratorios y reformulación de la idea de familia; pluralismo relativista en la concepción del matrimonio; influencia de los medios de comunicación sobre la cultura popular en la comprensión de la celebración del casamiento y de la vida familiar; tendencias de pensamiento subyacentes en la propuestas legislativas que desprecian la estabilidad y la fidelidad del pacto matrimonial [...]; nuevas interpretaciones de los derechos humanos. Pero, sobre todo, en ámbito más estrictamente eclesial, la debilitación o el abandono de fe en la sacramentalidad del matrimonio y en el poder terapéutico de la penitencia sacramental ${ }^{32}$.

La existencia en la Iglesia de personas casadas, que se sienten llamadas a vivir la radicalidad de la consagración bautismal desde un carisma, tiene mucho que aportar.

\section{BIBLIOGRAFÍA}

L. Grosso García (ed.), El soplo del Espíritu. Nuevas formas de vida consagrada en la Iglesia de España, Madrid 2010.

-Itinerarios del Espiritu. Experiencias y perspectivas de las Nuevas Formas de Vida Consagrada, Madrid 2013.

-Mirad cómo se aman. Las nuevas formas de vida consagrada en la comunión eclesial, Madrid 2015.

Seminario de NFVC, Multiforme armonía. Actualidad teológico-canónica de las Nuevas Formas de Vida Consagrada, Madrid 2015.

32. III Asamblea General Extraordinaria del Sínodo de los Obispos, Los desafíos pastorales sobre la familia en el contexto de la evangelización. Documento preparatorio, 2013. 